\title{
Dance lessons on a personal health budget
}

$\mathrm{E}$ ngland is preparing to roll out personal health budgets for continuing care patients to give them more control over the care they receive, including an option for individuals to receive direct cash payments with which to buy and manage services for themselves.

Personal health budgets, which have been piloted with more than 2700 National Health Service (NHS) patients across 64 primary care trusts since 2009 , provide patients with the option of receiving cash in lieu of conventionally managed health services with which to independently purchase and arrange the care they need and desire, including "therapies, personal care, lifestyle advice and self-management courses" (www.personalhealthbudgets .dh.gov.uk/_library/Resources/Personal healthbudgets/PHB_leaflet_amended _July_10.pdf).

Aimed at encouraging more "innovative and flexible approaches to meeting health and well-being outcomes," the cash can be used for any goods and services that are "likely to meet the individual's agreed healthcare outcomes and would be appropriate for the state to fund. This would, for example, exclude alcohol, cigarettes, gambling, debt repayment or any illegal item," according to the Department of Health (www .dh.gov.uk/prod_consum_dh/groups/dh _digitalassets/@dh/@en/@ps/documents /digitalasset/dh_117262.pdf).

According to 2012 data, about 53000 people are now receiving continuing care through the NHS (www.personalhealth budgets.dh.gov.uk/_library/Resources /Personalhealthbudgets/2012/Personal _health_budgets_and_CHC_discussion _paper.pdf). All of those people will be eligible for a personal health budget, "including a direct payment," by April 2014, subject to a full evaluation of the pilot to be released in October, Katrina Coutts, a press officer with the Department of Health, writes in an email.

Eligibility for continuing care status in Great Britain is restricted to those whose

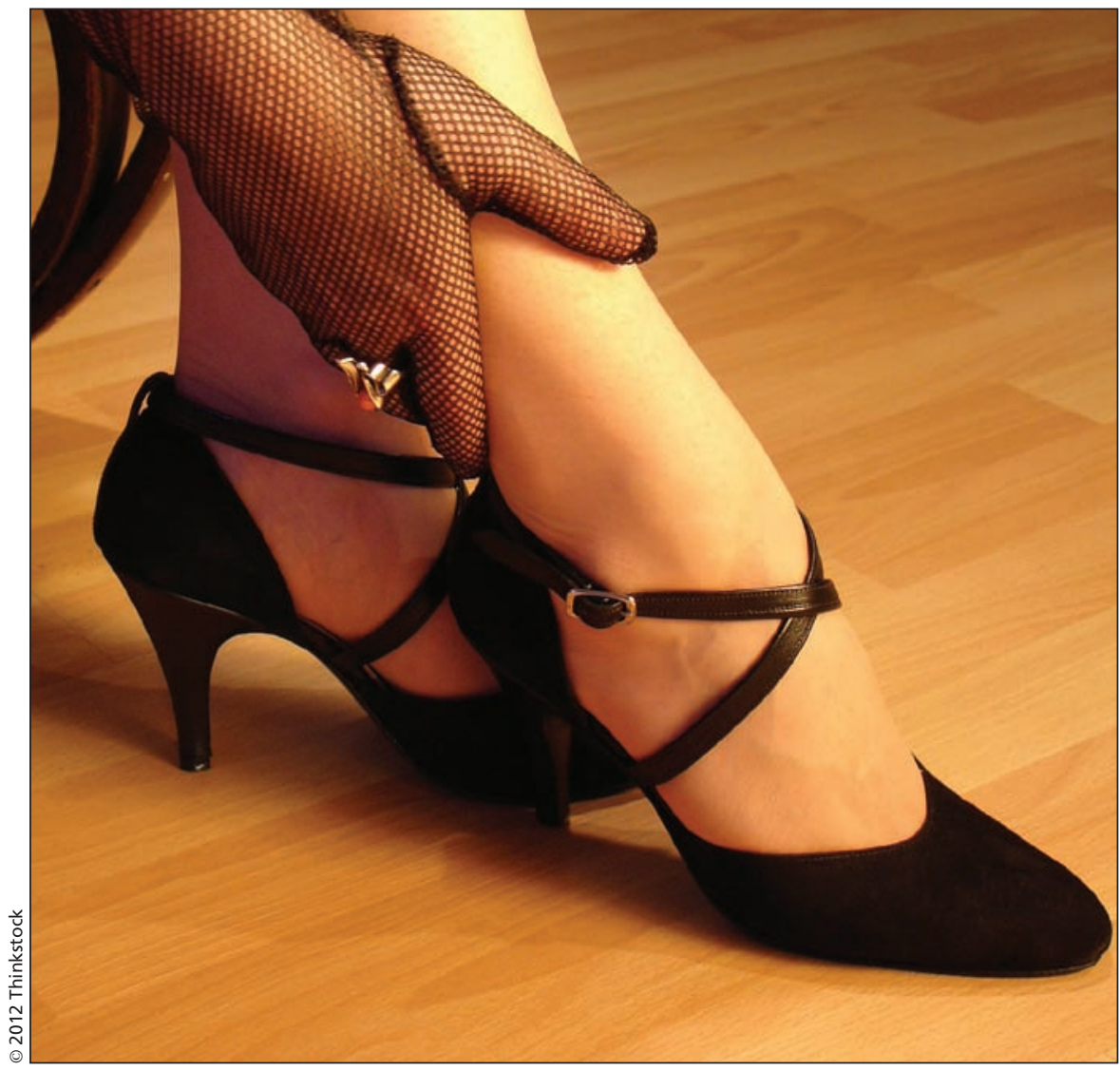

Under England's personal health budgets, a person with diabetes who is seeking to control their weight, for example, could use some of that money for such "radical" options as burlesque dancing classes.

"main or primary need for care" is related to their health (www.nhs.uk/Carers Direct/guide/practicalsupport/Pages/NHS ContinuingCare.aspx). "People who are eligible are likely to: have a complex medical condition that requires a lot of care and support; (and) need highly specialised nursing support," the NHS states. "Someone nearing the end of their life is also likely to be eligible if they have a condition that is rapidly getting worse and may be terminal. Eligibility for NHS continuing healthcare does not depend on: a specific health condition, illness or diagnosis; who provides the care, or where the care is provided. If you have a disability, or if you've been diagnosed with a long-term illness or condition, this doesn't necessarily mean that you'll be eligible for NHS continuing healthcare."
Skeptics warn that the extension of personal health budgets to all people who are eligible for continuing care may not be sustainable at a national level, and as an indicator of the potential perils, point to the exploding costs and fraud that has occurred within a similar system in the Netherlands.

They're calling for "firm and just" checks on who should be entitled to hold a personal health budget and how it can be used. They're also seeking concrete rules regarding what happens if a personal health budget is squandered and continuing care must still be provided.

But defenders of personal health budgets say the benefits outweigh their risks.

"It's so important for people, partic- 
ularly those with problems that already restrict their ability to live the life they want, to have autonomy, and the health care system should do what it can to accommodate that," says Peter Groenewegen, director of the Netherlands Institute for Health Services Research. Nevertheless, holding a personal health budget should not constitute an "open ended" entitlement, particularly to unproven or alternative therapies that patients otherwise would pay for privately, he adds.

England has already implemented personal budgets for social care recipients (generally defined as people who are vulnerable, disadvantaged or have special needs, including those with disabilities, those alcohol or drug dependency, the homeless or children and adolescents in residential care) and evaluations of the program have linked the approach to "better social care outcomes and higher perceived levels of control" among recipients (www.personalhealthbudgets.dh.gov .uk/_library/Resources/Personalhealth budgets/First_Steps_amended_July_10 .pdf).

But it's not clear whether the successes of personal budgets for social care will be readily transferable to the domain of continuing care, where an individual's health needs can be far more unpredictable, Dr. Martin McKee, a professor of European public health at the London School of Hygiene and Tropical Medicine in England, writes in an email. "It's just about possible to predict with some degree of certainty (but only some) what someone's social care expenditure will be next year, but almost impossible in health care. There is a real danger of pushing people into catastrophic expenditure."

That has occurred in the Netherlands, where patients have received direct payments for continuing care under a system of personal budgets since 1997.

The Dutch government is now overhauling the system in light of its spiraling costs, Groenewegen says, explaining that over the past decade, the number of Dutch budget holders has increased tenfold, while program expenditures have risen by an average $23 \%$ per year.

That runaway growth is partly attrib- utable to government's failure to set sufficiently strict eligibility requirements for the program, Groenewegen says. "There were a lot of people who asked for an assessment of their care needs [and received a personal care budget] who would not have asked for traditional formal care."

The program also failed to account for patients using their personal budgets to fund services they had once paid for out of their own pockets or received through informal arrangements.

"The assumption was that the PCB [a personal care budget in the Netherlands, or the equivalent of Britain's proposed personal health budgets] would be substitute care for the expensive traditional care," Klarita Sadiraj, a researcher at the Netherlands Institute for Social Research, writes in an email. "The introduction of this financial possibility may however have caused that more people claimed to have care needs financed by public money. Disabled people, who before the introduction of PCB would solve their care needs by informal care, would now claim their right for care using the PCB instead."

Personal health budget pilot sites in England reported average start-up costs of as much as $£ 93280$ over and above the costs that would have been incurred had the initiative not been implemented, according to an interim evaluation of the project (www.phbe.org.uk /documents/interim-report-jul-2011.pdf). But "it is assumed that as personal health budgets become more mainstream, the level of resource required will be reduced," the report added.

Projections as to exactly how much money an individual might conceivably receive under a national system of personal health budgets are equally difficult to pin down.

"The allocations to individuals can vary greatly as it could be money to pay for one-off small costs or could, for example, be for someone who needs 24/7 care," Coutts writes. However, "personal health budgets are not about new money, they are about using money that would have been spent on an individual's NHS funded care in different ways."

But some personal budget holders may see things differently.
Being able to purchase nontraditional health care - such as acupuncture, reflexology or aromatherapy was "central to some understanding of personal health budgets and a key factor in deciding to try a personal health budget ... Conversely, others felt it would be 'cheeky' or 'naughty' to use their budget for items outside conventional healthcare, including alternative medicines," according to a preliminary report on the pilot project (www.dh.gov .uk/prod_consum_dh/groups/dh_digital assets/documents/digitalasset/dh_1305 89.pdf).

Currently, it is up to primary care trusts to determine what services are "valid" for purchase using a personal health budget (www.personalhealth budgets.dh.gov.uk/_library/Resources /Personalhealthbudgets/Local_proces ses_-_deciding_what_to_spend_PHB _on.pdf). For example, a person with diabetes may have an agreed outcome around weight management which could be addressed in a number of different ways, including:

- the "traditional option" of seeing a dietitian

- the "different option" of joining an online diet service

- the "radical option" of taking burlesque dancing classes.

But failing to set clear limits on personal health budget spending and services, particularly alternative therapies, before the scheme is implemented nationally may result in existing evidence-based services becoming "less viable" as public monies are spent on a wider range of offerings, says Celestine Laporte, national officer for health at UNISON, Britain's largest public sector trade union.

It may eventually prove a burden on the acute care system, should patients fail to manage their conditions using alternative therapies, Laporte adds.

Moreover, because government has promised no one will be denied care if their budget runs out, the system provides little incentive against waste, she charges.

Laporte also questions the extent to which patients, particularly those with complex illnesses or mental health problems, are capable of managing their own care. "We've heard through various 
reports that staff need a lot more training in how to manage budgets on behalf of patients, and service users need access to a lot more information."

Some patients participating in England's pilot have reported feeling "anxious" about their ability to manage their own care, including "being able to find appropriate sources of care," according to another interim report (www.personalhealthbudgets .dh.gov.uk/_library/Resources/Personal healthbudgets/2011/Personal_health _budgets_4th_interim_evaluation_report .pdf).

That was also the experience in the Netherlands, where some patients reported they felt overwhelmed by the complexity of managing their personal budgets and so turned to private organizations to broker their care, which have a financial interest in driving up costs, Groenewegen says.

Laporte says there's been relatively little scrutiny in either jurisdiction of how personal health budgets are used, either by patients or their intermediaries. England has proposed a "once yearly check, which seems really quite a long time," considering the potential for fraud, she adds.
As an example of the potential for abuse, Laporte cites a Florida personal health budget project that was "shut down because there was all sorts of ... corruption, untoward goings on and people spending their budgets on pole dancing or holidays."

Abuses have also extended to intermediaries. In the Netherlands, Groenewegen notes, there have been highly publicized cases in which "intermediary organizations applied for personal budgets for clients who didn't even know that a personal budget was asked for them," and "health providers made up [fraudulent] assessments ... and somehow also had an advantage out of that."

In such cases, commissioners in England will have the option of issuing a warning to the personal health budget holder; requiring an alternative intermediary be found; withdrawing the budget and offering conventionally managed services; or, where the misuse of funds is considered "significant," asking that the money be repaid (www .dh.gov.uk/prod_consum_dh/groups/dh _digitalassets/@dh/@en/@ps/documents /digitalasset/dh_117262.pdf).

Groenewegen contends that many cases of fraud can be prevented by creating a public brokerage system to liaison between patients and care providers, or simplifying the administrative tasks involved in managing personal budgets so that more patients can oversee their spending independently of possibly "unscrupulous" third parties. Patients should also be provided clear guidelines on their responsibilities when they hire a care provider, he adds.

Care providers, Laporte contends, are invariably disadvantaged by the fact they are being "forced down the road of being directly employed by service users."

"We're finding there's a minimum wage culture being developed among personal assistants," as patients "want to get the maximum amount" of value from their budgets, she explains.

England is currently piloting other models of personal health budgets, including ones managed by physicians on behalf of the budget holders.

But generally, "there is a clear Government commitment to make personal health budgets, including direct payments, more widely available," Coutts writes. — Lauren Vogel, CMAJ

CMAJ 2012. DOI:10.1503/cmaj.109-4172 